\title{
miR-877-5p antagonizes the promoting effect of SP on the gastric cancer progression
}

\author{
Xiao-Dan GUO, Nan ZHANG, Lei SHA* \\ Department of Neuroendocrine Pharmacology, School of Pharmacy, China Medical University, Shenyang, China \\ ${ }^{*}$ Correspondence: pharmacology333@126.com
}

Received May 2, 2020 / Accepted June 8, 2020

\begin{abstract}
Gastric cancer is one of the four major tumors in the world and the second leading cause of cancer-related death. It was reported that Substance P (SP), as an oncogenic factor, could regulate the expression of miRNAs in gastric cancer progression. Here, we focused on the role of miR-877-5p in gastric cancer development and the miR-877-5p involvement in the SP-mediated gastric cancer development. The mRNA expression level and cell proliferation were assessed by quantitative real-time PCR and cell counting kit- 8 assay, respectively. Flow cytometry was conducted to detect apoptosis, followed by assessing the expression of related apoptosis factors. Dual-luciferase reporter assay was performed to validate the interaction between miR-877-5p and Forkhead cassette M1 (FOXM1). Our results showed that SP treatment significantly increased cell proliferation in gastric cancer. Moreover, the miR-877-5p expression was dose-dependently decreased by SP, whereas FOXM1 expression was markedly increased by SP in gastric cancer cells. miR-877-5p negatively regulated gastric cancer development via inhibiting cell proliferation and promoting apoptosis accompanied by increased cleaved caspase-3, cleaved caspase-9, and Bax protein levels and decreased Bcl-2 level. We confirmed that miR-877-5p could target FOXM1 and negatively regulate its expression. Furthermore, we demonstrated that SP could promote cell proliferation and inhibit apoptosis, while miR-877-5p overexpression reversed the effect of SP on cell proliferation and apoptosis. These results suggest that miR-877-5p overexpression can antagonize the promoting effect of SP on the development of gastric cancer, indicating that miR-877-5p may serve as a promising therapeutic target for gastric cancer.
\end{abstract}

Key words: gastric cancer, Substance P, miR-877-5p, cell proliferation, apoptosis

Gastric cancer is one of the most common malignancies in the digestive system and the second leading cause of cancer-related death $[1,2]$. According to the global incidence and mortality of gastric cancer updated by the International Agency for Research on Cancer (IARC) in 2008 [3], gastric cancer accounts for $7.8 \%$ of all reported cancer cases, making it the fourth most common malignancy in the world after lung cancer, breast cancer, and colorectal cancer [4]. Etiologically, Helicobacter pylori infection, dietary and lifestyle factors, and genetics and ethnicity are all factors affecting the development of gastric cancer [4]. Currently, traditional cancer treatments, including surgical resection of the primary tumor, radiotherapy, and chemotherapy, offer the only chance of cure in cancer progression $[5,6]$. Therefore, new treatments should be developed to solve this global problem.

Substance P (SP) belongs to the tachykinin family of peptides and plays an important role in tumor cell proliferation, apoptosis, angiogenesis, invasion, and metastasis [7-9]. Neurokinin-1 (NK-1) receptor (NK-1R) belongs to the family of $\mathrm{G}$ protein-coupled receptors, which has a high affinity to SP [10]. SP and NK-1R are present in human gastric cancer or normal gastric cells $[11,12]$. A previous study found that $\mathrm{SP}$, after binding to the NK-1R, could induce proliferation of gastric cancer cells [11]. Besides, in vitro studies have demonstrated that SP promoted the proliferation, adhesion, migration, and invasion in human gastric cancer cells [13]. Meanwhile, in vivo studies indicated that a significant increase in the incidence of gastric cancer was observed after long-term injection of SP in Wistar rats [14]. Therefore, SP plays a promoting role in the development of gastric cancer.

microRNAs (miRNAs) are 21-23 nucleotide-long singlestranded non-coding RNA molecules that regulate target molecules and genes involved in cellular processes, including inflammation, cell cycle regulation, stress response, differentiation, apoptosis, and migration through translation inhibition and mRNA destabilization [15-17]. Many miRNAs are dysregulated during cancer development and act as oncogenes or tumor suppressor genes. Especially, 
miR-877-5p was downregulated in the blood and tissues of patients with renal cell carcinoma [18]. Moreover, miR-877-5p played a tumor-inhibiting role in hepatocellular carcinoma by targeting Forkhead cassette M1 (FoxM1) [19]. Besides, dysregulated miR-877-5p has also been observed in other cancers, including liver cancer, kidney cancer, and bladder cancer $[18,20,21]$. However, whether miR-877-5p is involved in the development of gastric cancer remains unknown. In addition, studies have found that some miRNAs in cancer cells were regulated by SP. Specifically, SP could downregulate the expression of miR-877-5p in human colon epithelial cells [22]. However, whether SP regulates the expression of miR-877 in gastric cancer cells remains unclear. Therefore, in the present study, we investigated the role of miR-877-5p in gastric cancer progression and determined whether miR-877-5p was involved in the SP-mediated development of gastric cancer.

In the current study, we investigated: 1) the role of SP treatment in cell proliferation and miR-877-5p expression in gastric cancer; 2) the role of miR-877-5p overexpression or knockdown in cell proliferation and apoptosis in gastric cancer; 3 ) the role of miR-877-5p overexpression or knockdown in proliferation and apoptosis in SP-treated gastric cancer cells.

\section{Materials and methods}

Cell lines and treatment. Our study did not require ethical board approval because it did not contain human or animal trials. Gastric cancer cell lines MGC-803, MKN45, and HGC-27 were purchased from Procell (Wuhan, China). All cell lines were cultured in RPMI-1640 (Gibco, 31800-014, USA) medium containing 10\% fetal bovine serum (Hyclone, $\mathrm{SH} 30084.03$, USA) in an incubator at $37^{\circ} \mathrm{C}$ supplied with $5 \%$ $\mathrm{CO}_{2}$. For SP treatment, MGC-803 and MKN45 cells were treated with $100 \mathrm{nM}$ SP for $0,6,12,24,48$, and $72 \mathrm{~h}$ or cells were treated with $\mathrm{SP}(0,5,10,50$, and $100 \mathrm{nM})$ for $48 \mathrm{~h}$.

Oligonucleotides and transfection. Synthetic miR-877-5p mimics, inhibitor, and their corresponding negative control (NC) were purchased from Jintuosi Biological Technology Co., Ltd. (Wuhan, China). The transfections and co-transfections were mediated by Lipofectamine ${ }^{\circledast}$ 2000 (Invitrogen, 11668-019, USA). For the transfection, miR-877-5p mimics, inhibitor, or its corresponding NC was transfected into MKN45 and MGC-803 cells for 48 h. For the co-transfection, the plasmid was co-transfected with

Table 1. Oligonucleotide sequences.

\begin{tabular}{ll}
\hline Name & Sequences \\
\hline miR-877-5p mimics & 5'-GUAGAGGAGAUGGCGCAGGG-3' \\
& 5'-CUGCGCCAUCUCCUCUACUU-3' \\
mimics NC & 5'-UUCUCCGAACGUGUCACGUTT -3' \\
& 5'-ACGUGACACGUUCGGAGAATT-3' \\
miR-877-5p inhibitor & 5'-CCCUGCGCCAUCUCCUCUAC-3' \\
inhibitor NC & 5'-UUGUACUACACAAAAGUACUG-3' \\
\hline
\end{tabular}

miR-877-5p mimics, inhibitor, or its corresponding NC into MKN45 and MGC-803 cells for $48 \mathrm{~h}$. Oligonucleotide sequences are shown in Table 1.

Western blot analysis. Western blot was performed to detect protein levels. Briefly, cells were lysed using RIPA buffer (Solarbio, R0010, China). The total protein concentration was detected by BCA protein concentration assay kit (Solarbio, PC0020, China). SDS-polyacrylamide gel electrophoresis (SDS-PAGE, 10\% gel, $20 \mu \mathrm{g} /$ lane) was then performed to separate protein extracts. After electrophoresis, the proteins were transferred to PVDF membranes (Millipore, IPVH00010, USA) and blocked at room temperature with 5\% skim milk dissolved in TBST (TBS with $0.1 \%$ Tween-20) for $2 \mathrm{~h}$. Subsequently, the membranes were incubated with primary antibodies in TBST containing $0.5 \%$ skim milk at $4{ }^{\circ} \mathrm{C}$ overnight. After washing with TBST four times ( $5 \mathrm{~min} /$ time), the membranes were incubated with HRP-conjugated anti-rabbit secondary antibodies (1:5000, Solarbio, SE134) and GAPDH was incubated with HRP-conjugated anti-mouse secondary antibody (1:5000, Solarbio, SE131) for $2 \mathrm{~h}$ at room temperature. After washing six times with TBST (5 min/time), the membranes were treated with ECL luminescence solution (Solarbio, PE0010, China) for chemiluminescence. The expression levels of the target proteins were normalized to the GAPDH level. Optical density values of target bands were analyzed using Gel image processing system (Gel-Pro-Analyzer software). The primary antibodies used in present study were as follows: NK-1R (1:1000, Proteintech, 17942-1-AP), Caspase-3 (1:1000, Cell Signaling Technology (CST), \#14220), Caspase-9 (1:1000, CST, \#9502), Bcl-2 (1:2000, Proteintech, 12789-1-AP), Bax (1:5000, Proteintech, 50599-2-1g), FOXM1 (1:1000, Proteintech, 13147-1-AP), and GAPDH (1:10000, Proteintech, 60004-1-Ig).

Cell Counting Kit-8 (CCK-8). Gastric cancer cells were inoculated in 96 -well plates at a density of $4 \times 10^{3}$ cells/well. Cells transfected with miR-877-5p mimics, mimics negative control (NC), miR-877-5p inhibitor, or inhibitor NC continued the incubation at $37^{\circ} \mathrm{C}$ supplied with $5 \% \mathrm{CO}_{2}$ for $0,6,24,48$, and $72 \mathrm{~h}$. Subsequently, CCK-8 solution (10 $\mu \mathrm{l}$, Keygen Biotech, KGA317, China) was added to each well, and cells were cultured in an incubator at $37^{\circ} \mathrm{C}$ supplied with $5 \% \mathrm{CO}_{2}$ for $2 \mathrm{~h}$. Finally, the OD value at $450 \mathrm{~nm}$ was determined on a microplate reader (Biotek, ELX-800, USA).

Quantitative Real-Time PCR (qRT-PCR). qRT-PCR was performed to detect the relative levels of the transcripts (miR-877-5p and FOXM1). In brief, total RNA was extracted from the MGC-803 and MKN45 cells using the total RNA extraction kit (Tiangen, DP419, China) according to the manufacturer's protocols. To detect the miR-877-5p expression level, complementary DNA (cDNA) was generated. The temperature protocol for reverse transcription was as follows: $37^{\circ} \mathrm{C}$ for $30 \mathrm{~min}, 42^{\circ} \mathrm{C}$ for $30 \mathrm{~min}$, and $70^{\circ} \mathrm{C}$ for $10 \mathrm{~min}$. Subsequently, to determine the miR-877-5p expression level, qRT-PCR was performed. The temperature protocol for 
qRT-PCR was as follows: $94^{\circ} \mathrm{C}$ for 2 min, 40 cycles of $94^{\circ} \mathrm{C}$ for $15 \mathrm{~s}, 60^{\circ} \mathrm{C}$ annealing temperature for primer pairs for $15 \mathrm{~s}$ and $72^{\circ} \mathrm{C}$ for $15 \mathrm{~s}$.

The cDNA was obtained to determine the FOXM1 expression. The temperature protocol for reverse transcription was as follows: $25^{\circ} \mathrm{C}$ for $10 \mathrm{~min}, 42^{\circ} \mathrm{C}$ for $50 \mathrm{~min}$, and $80^{\circ} \mathrm{C}$ for $10 \mathrm{~min}$. The qRT-PCR was performed to analyze FOXM1 mRNA expression. The temperature protocol for qRT-PCR was as follows: $94^{\circ} \mathrm{C}$ for $5 \mathrm{~min}, 40$ cycles of $94^{\circ} \mathrm{C}$ for $10 \mathrm{~s}$, $60^{\circ} \mathrm{C}$ annealing temperature for primer pairs for $20 \mathrm{~s}$ and $7^{\circ} \mathrm{C}$ for $30 \mathrm{s.} \mathrm{U6}$ and GAPDH were used as internal controls to standardize the expression of miR-877-5p and FOXM1, respectively, in each sample. Quantification of gene expression was determined using the $2^{-\Delta \Delta \mathrm{Ct}}$ comparative method. The primers (GenScrip, China) for qRT-PCR are shown in Table 2.

Flow cytometry analysis. The cells were inoculated in 6-well plates at a density of $1 \times 10^{5}$ cells/well and transfected with miR-877-5p mimics, mimics NC, miR-877-5p inhibitor, or inhibitor NC for $48 \mathrm{~h}$. Subsequently, cells were doublestained using an apoptosis detection kit (Beyotime, C1062, China) according to the manufacturer's protocols. Cells stained with annexin V-FITC and PI were analyzed by flow cytometry (Aceabio, NovoCyte, USA).

Luciferase reporter assay. The wild type FOXM1-3'Untranslated Region (UTR) sequence and the mutated FOXM1-3'-UTR sequence were cloned into the pmirGLO dual-luciferase reporter vectors to construct the pmirGLOFOXM1-3'-UTR-wild-type (WT) and pmirGLO-FOXM13'-UTR-mutant (MUT) plasmids. The recombinant plasmid was co-transfected into MKN45 or MGC-803 cells with miR-877-5p mimics, mimics NC, miR-877-5p inhibitor, or inhibitor NC, respectively, using Lipofectamine 2000 (Invitrogen). The cells were inoculated into 12 -well plates at a density of $1 \times 10^{5}$ cells/well. After $48 \mathrm{~h}$ treatment, the transfected cells were collected and luciferase activity was measured using a dual-luciferase assay kit (Promega, E1910, USA). Luciferase activity was measured by Firefly luciferase/ Renilla luciferase.

Statistical analysis. The students' $t$-test was used to analyze the differences between the two groups. One-way ANOVA and two-way ANOVA were used to determine the statistical significance between three or more groups. GraphPad 8.0 was used for all statistical tests. A p-value $<0.05$ was considered as statistical significance, data were presented as means \pm standard deviation (SD). All the experiments were performed with three experimental replicates.

\section{Results}

SP promoted cell proliferation and decreased the expression of miR-877-5p in gastric cancer. In the present study, NK-1R levels in gastric cancer cell lines HGC-27, MGC-803, and MKN45 were detected, and two cell lines MGC-803 and MKN45 with a relative higher protein level of NK-1R were
Table 2. qRT-PCR primer sequences.

\begin{tabular}{|c|c|}
\hline Gene & Primer sequences \\
\hline hsa-miR-877-5p & $\begin{array}{l}\text { forward: 5’- GTAGAGGAGATGGCGCAGGG -3' } \\
\text { reverse: 5'- GCAGGGTCCGAGGTATTC -3' }\end{array}$ \\
\hline U6 & $\begin{array}{l}\text { forward: 5'- GCTTCGGCAGCACATATACT -3' } \\
\text { reverse: 5'- GCAGGGTCCGAGGTATTC -3' }\end{array}$ \\
\hline FOXM1 & $\begin{array}{l}\text { forward: 5'- CGAAAGATGAGTTCTGATGG -3' } \\
\text { reverse: 5'- CTGTTGATGGCGAATTGTAT -3' }\end{array}$ \\
\hline GAPDH & $\begin{array}{l}\text { forward: 5'- GACCTGACCTGCCGTCTAG -3' } \\
\text { reverse: 5'- AGGAGTGGGTGTCGCTGT -3' }\end{array}$ \\
\hline
\end{tabular}

selected (Figure 1A). After treatment with SP for 0, 6, 12, 24, 48 , and $72 \mathrm{~h}$, the viability of MGC-803 and MKN45 cells was increased, and the increase was especially significant after 48 $\mathrm{h}$ of SP treatment (Figure 1B, p $<0.05$ ). After treatment with $\mathrm{SP}(0,5,10,50$, and $100 \mathrm{nM})$ for $48 \mathrm{~h}$, the expression level of miR-877-5p in MGC-803 and MKN45 cells was detected by qRT-PCR, and the results showed that miR-877-5p expression level was dose-dependently decreased by SP (Figure 1C, $\mathrm{p}<0.05)$. Meanwhile, the mRNA and protein expression levels of FOXM1 in MGC-803 and MKN45 cells were also markedly reduced by SP (Figure $1 \mathrm{D}, \mathrm{p}<0.05$ ). Therefore, the results indicated that $\mathrm{SP}$ plays a promoting role in gastric cancer development and negatively regulates miR-877-5p expression, while SP positively regulates FOXM1 expression.

miR-877-5p inhibited cell proliferation and promoted apoptosis in gastric cancer. To explore the role of miR-877-5p in the development of gastric cancer, gastric cancer cell lines MGC-803 and MKN45 were transfected with miR-877-5p mimics, mimics NC, miR-877-5p inhibitor, or inhibitor NC for $48 \mathrm{~h}$ (Figure 2A). The results of the CCK- 8 assay showed that the miR-877-5p overexpression inhibited cell proliferation, whereas miR-877-5p knockdown had the opposite effect (Figure $2 \mathrm{~B}, \mathrm{p}<0.05$ ). The apoptosis was detected by flow cytometry, and the results showed that miR-877-5p overexpression promoted apoptosis, whereas miR-877-5p silencing inhibited apoptosis in gastric cancer cells (Figures $2 \mathrm{C}-2 \mathrm{~F}$, $\mathrm{p}<0.05$ ). Meanwhile, the protein levels of the apoptosis promotors, cleaved caspase- 3 , cleaved caspase-9, and Bax were increased by miR-877-5p overexpression, whereas their expression levels were decreased in miR-877-5p-silenced cells (Figures $3 \mathrm{~A}-3 \mathrm{C}, \mathrm{p}<0.05$ ). In contrast, the protein expression level of the apoptosis suppressor Bcl-2 was decreased in miR-877-5p overexpressed cells, whereas its level was increased in miR-877-5p-silenced cells (Figures 3A-3C, $\mathrm{p}<0.05$ ). Our results suggest that miR-877-5p negatively regulates gastric cancer development through inhibiting cell proliferation and inducing apoptosis.

miR-877-5p suppressed the expression of its target gene FOXM1. We further detected the targeting relationship between miR-877-5p and FOXM1 by dual-luciferase reporter assay in MGC-803 and MKN45 cells. The predicted binding sites of miR-877-5p on FOXM1 mRNA are shown (Figure 4A). The results showed that the relative luciferase intensity in miR-877-5p mimics + FOXM1 WT group was 

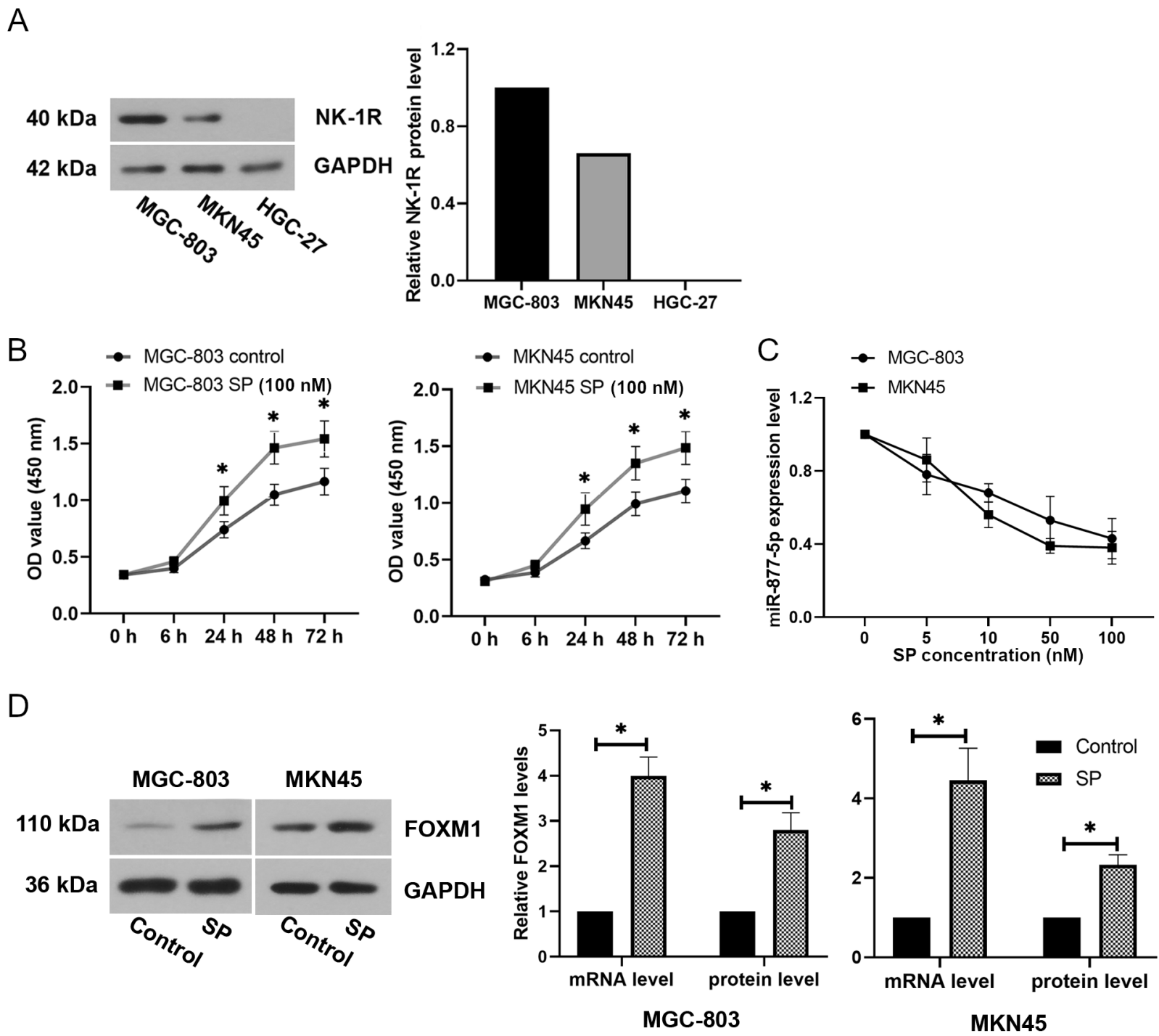

Figure 1. SP promoted cell proliferation and decreased the expression of miR-877-5p in gastric cancer. A) The relative protein expression level of NK$1 \mathrm{R}$ was quantified by densitometry in MGC-803, MKN45, and HGC-27 cells. B) MGC-803 and MKN45 cell vitality after treatment with SP (100 nM) for $0,6,12,24,48$, and $72 \mathrm{~h}$. C) The relative expression level of miR-877-5p in MGC-803 and MKN45 cells after treatment with SP $(0,5,10,50$, and 100 $\mathrm{nM})$ for $48 \mathrm{~h}$. D) Relative mRNA and FOXM1 expression levels in MGC-803 and MKN45 cells after treated with SP (100 nM) for $48 \mathrm{~h}$. Data are means $\pm \mathrm{SD}, \mathrm{n}=3$. ${ }^{*} \mathrm{p}<0.05$ compared with the control group.

significantly lower than that in mimics NC + FOXM1 WT and miR-877-5p mimics FOXM1 MUT groups (Figure 4B, $\mathrm{p}<0.05)$, indicating that there is a direct targeting relationship between miR-877-5p and FOXM1. Besides, the effect of miR-877-5p overexpression or knockdown on FOXM1 expression in MGC-803 and MKN45 cells was examined by qRT-PCR and western blot, respectively. Our results showed that miR-877-5p overexpression decreased the mRNA and protein levels of FOXM1 in both MGC-803 and MKN45 cells, whereas their levels were increased in miR-877-5p-silenced cells (Figures $4 \mathrm{C}, 4 \mathrm{D}, \mathrm{p}<0.05$ ). The results suggested that miR-877-5p can target FOXM1 and negatively regulate its level.
miR-877-5p antagonized the effect of SP on gastric cancer cells. We further explored the regulatory relationship between miR-877-5p and SP in the development of gastric cancer. MGC0803 and MKN45 cell vitality after SP treatment of cells transfected with miR-877-5p mimic (Figure 5A). The results showed that the upregulation of miR-877-5p inhibited SP-induced cell proliferation and attenuated SP-mediated inhibition of apoptosis (Figures 5B-5D, $\mathrm{p}<0.05$ ). Besides, SP treatment decreased cleaved caspase- 3 and cleaved caspase- 9 protein levels, which was reversed by the miR-877-5p overexpression (Figures $5 \mathrm{E}-5 \mathrm{G}, \mathrm{p}<0.05$ ). The results suggested that miR-877-5p could antagonize the effect of SP on the development of gastric cancer. 
A

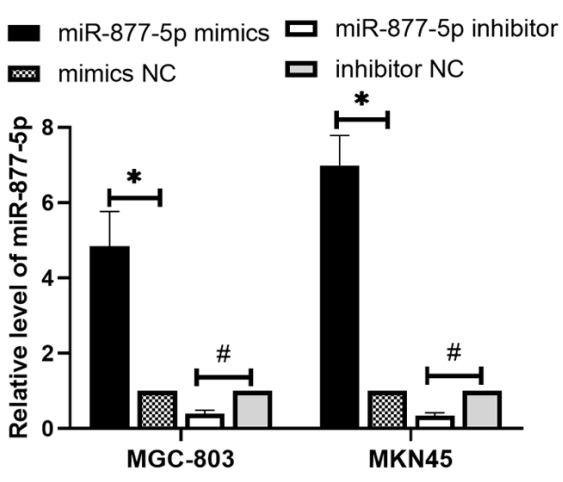

C

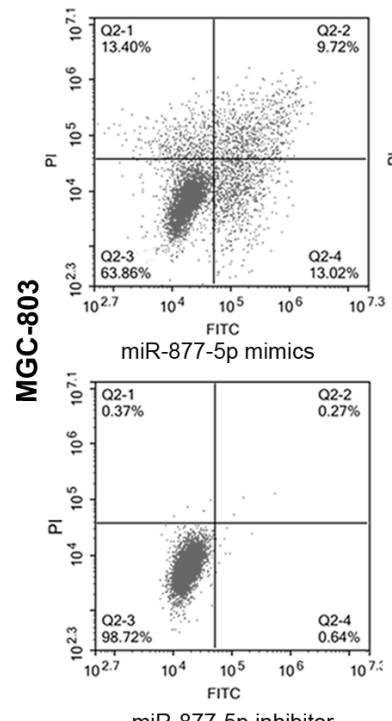

$E$
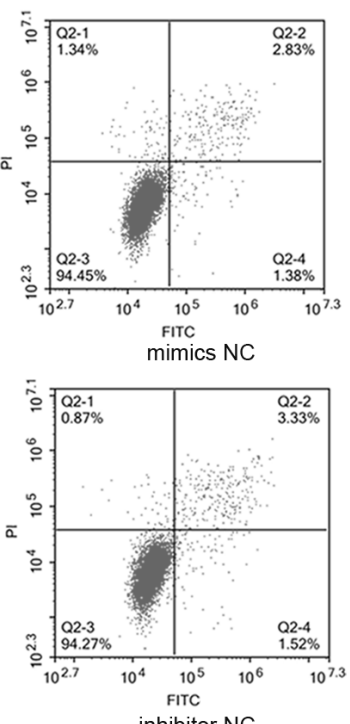

inhibitor NC

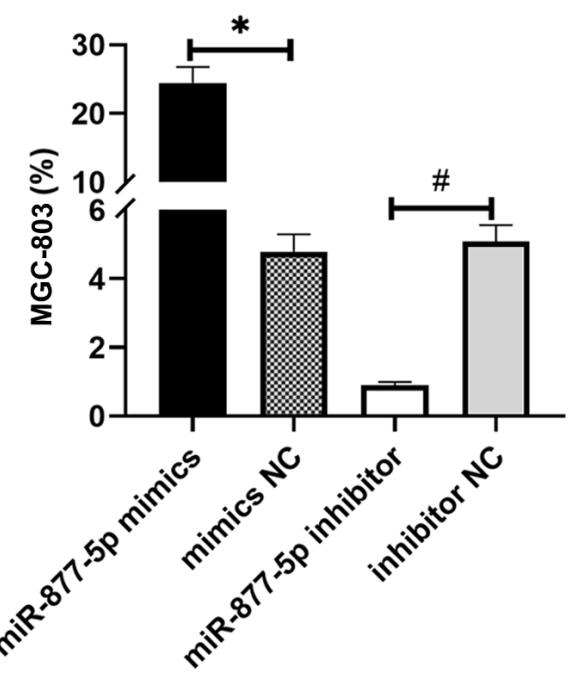

B
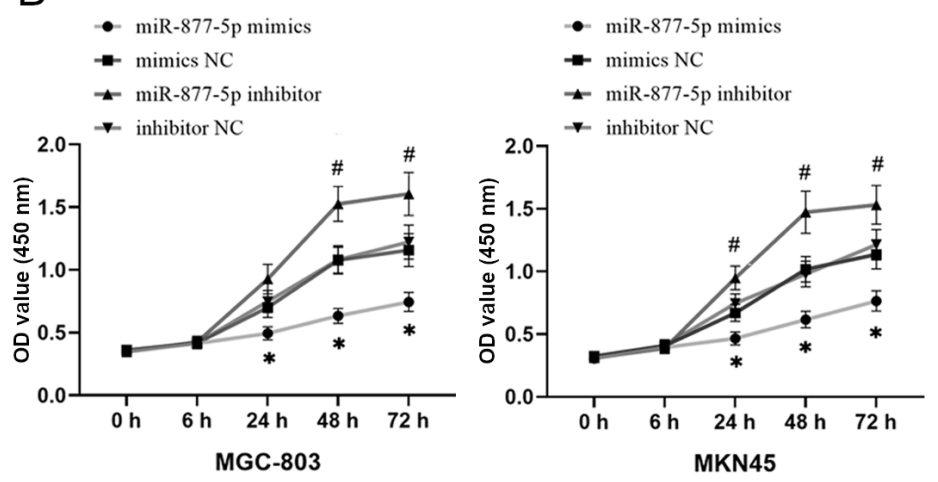

D
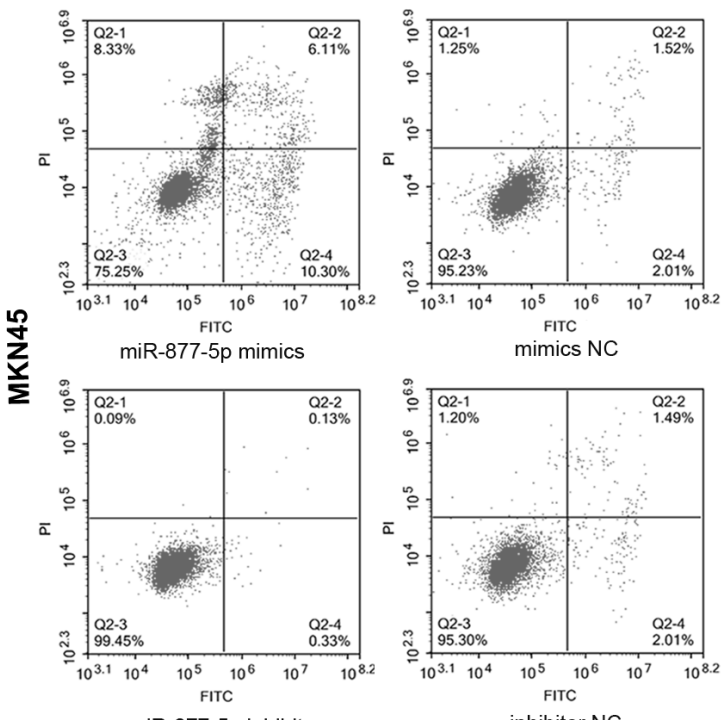

$\mathrm{F}$

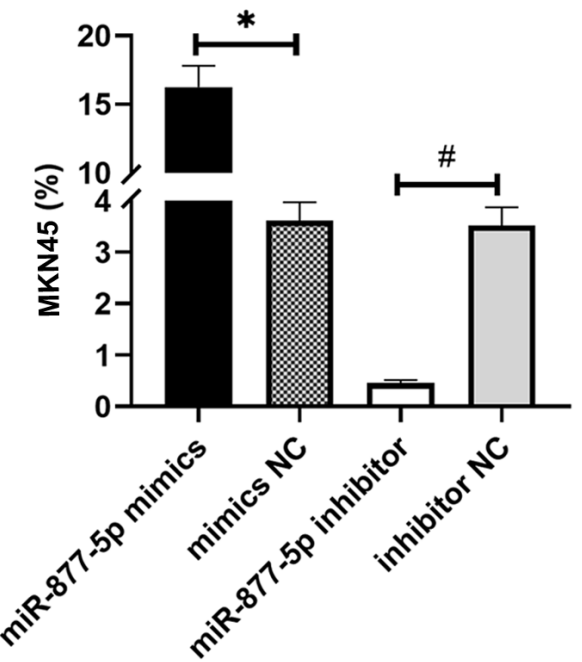

Figure 2. miR-877-5p inhibited cell proliferation and promoted apoptosis in gastric cancer. A) The relative expression level of miR-877-5p after MGC803 and MKN45 cells were transfected with miR-877-5p mimics, mimics NC, miR-877-5p inhibitor, or inhibitor NC for 48 h. B) MGC-803 and MKN45 cell vitality after cells were transfected with miR-877-5p mimics, mimics NC, miR-877-5p inhibitor, or inhibitor NC for 0, 6, 12, 24, 48, and 72 h. C-F) Flow cytometry assay of apoptosis in MGC-803 and MKN45 cells after transfected with miR-877-5p mimics, mimics NC, miR-877-5p inhibitor, or inhibitor NC for $48 \mathrm{~h}$. Data are means $\pm \mathrm{SD}, \mathrm{n}=3$. ${ }^{*} \mathrm{p}<0.05$ compared with the mimics $\mathrm{NC}$ group, ${ }^{*} \mathrm{p}<0.05$ compared with the inhibitor NC group. 
A
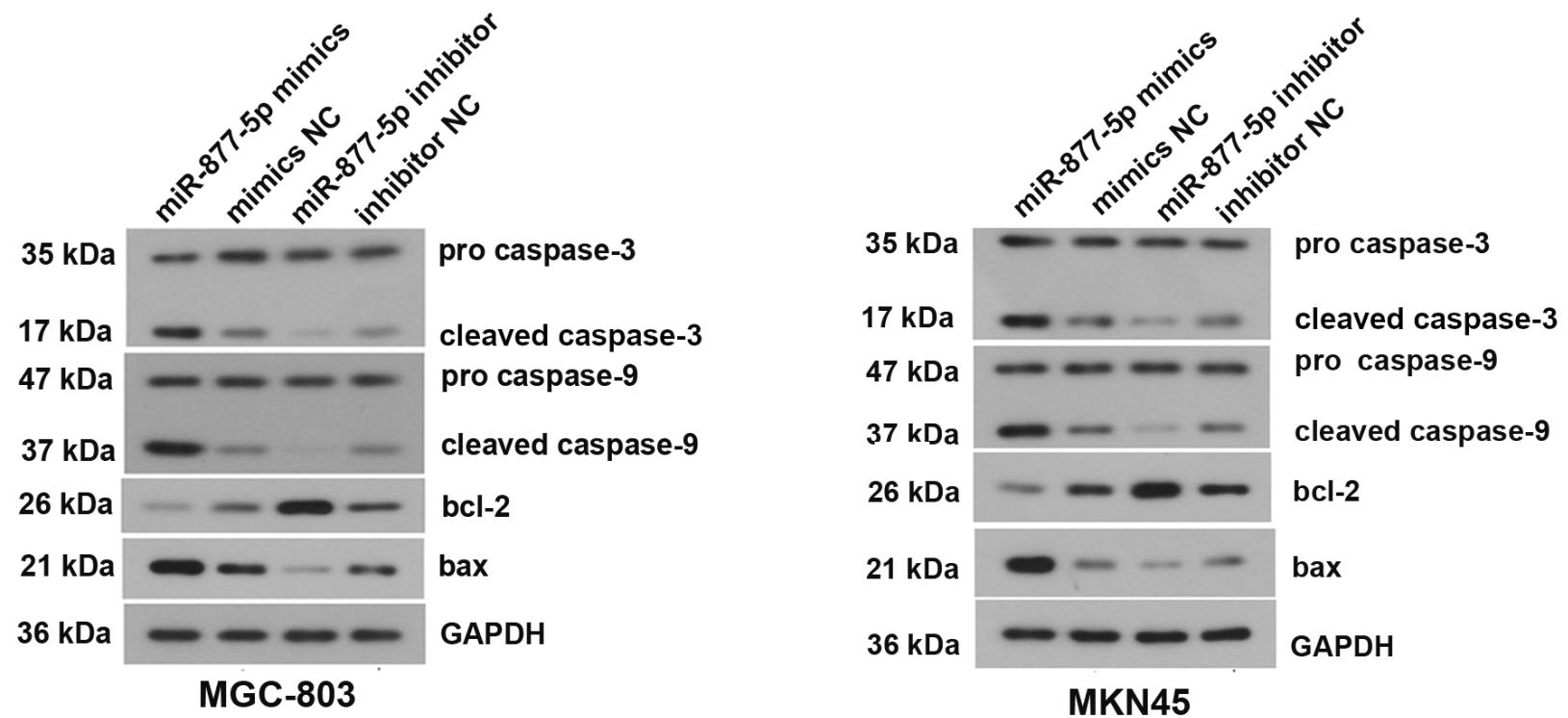

B

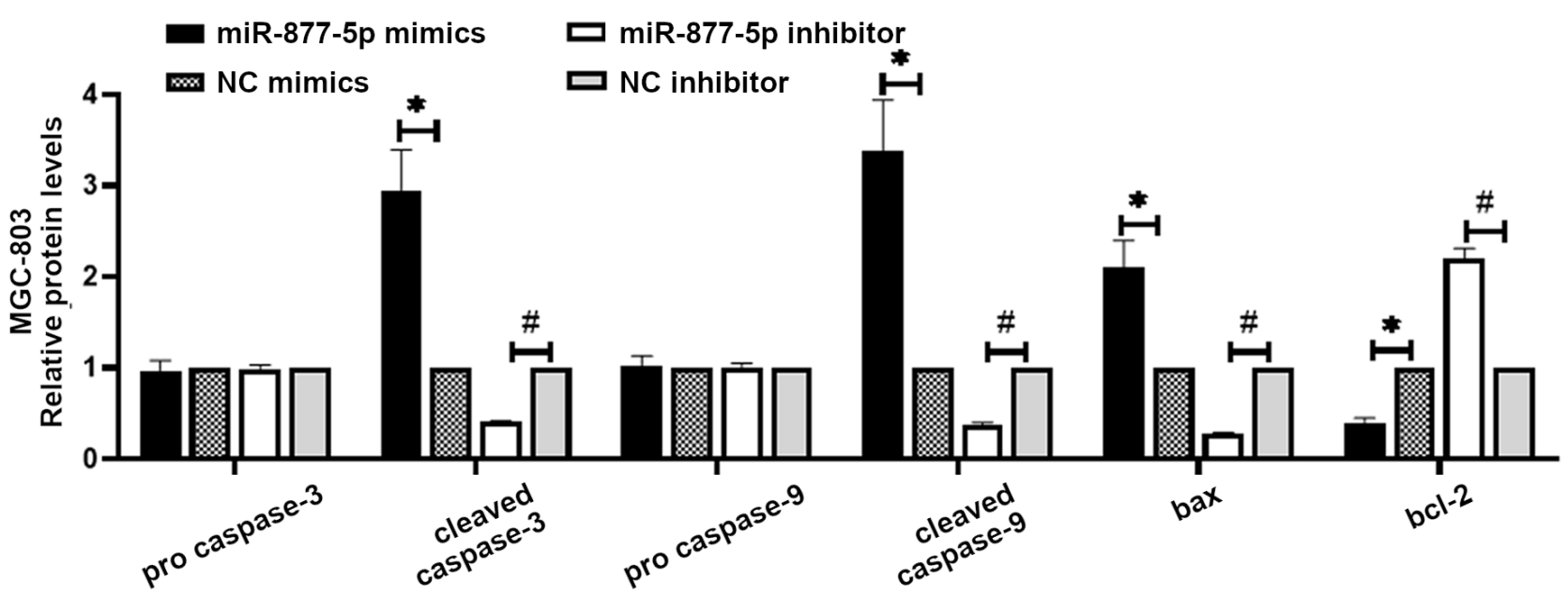

C

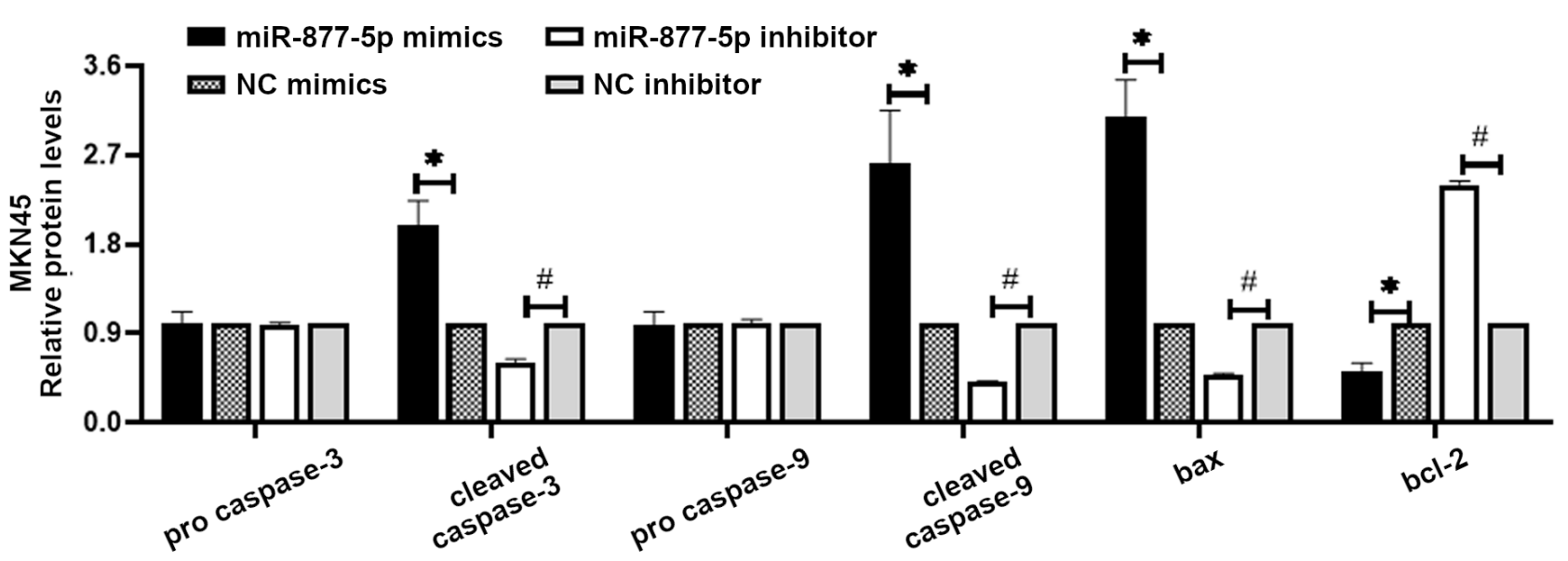

Figure 3. miR-877-5p inhibited apoptosis in gastric cancer. A) Representative immunoblots of pro caspase-3, cleaved caspase-3, pro caspase-9, cleaved caspase-9, Bax, and Bcl-2 after MGC-803 and MKN45 cells were transfected with miR-877-5p mimics, mimics NC, miR-877-5p inhibitor, or inhibitor NC for $48 \mathrm{~h}$. B, C) The relative amounts of protein were quantified by densitometry and normalized to the level of GAPDH in MGC-803 and MKN45 cells. Data are means $\pm \mathrm{SD}, \mathrm{n}=3$. ${ }^{*} \mathrm{p}<0.05$ compared with the mimics $\mathrm{NC}$ group, ${ }^{\#} \mathrm{p}<0.05$ compared with the inhibitor NC group. 

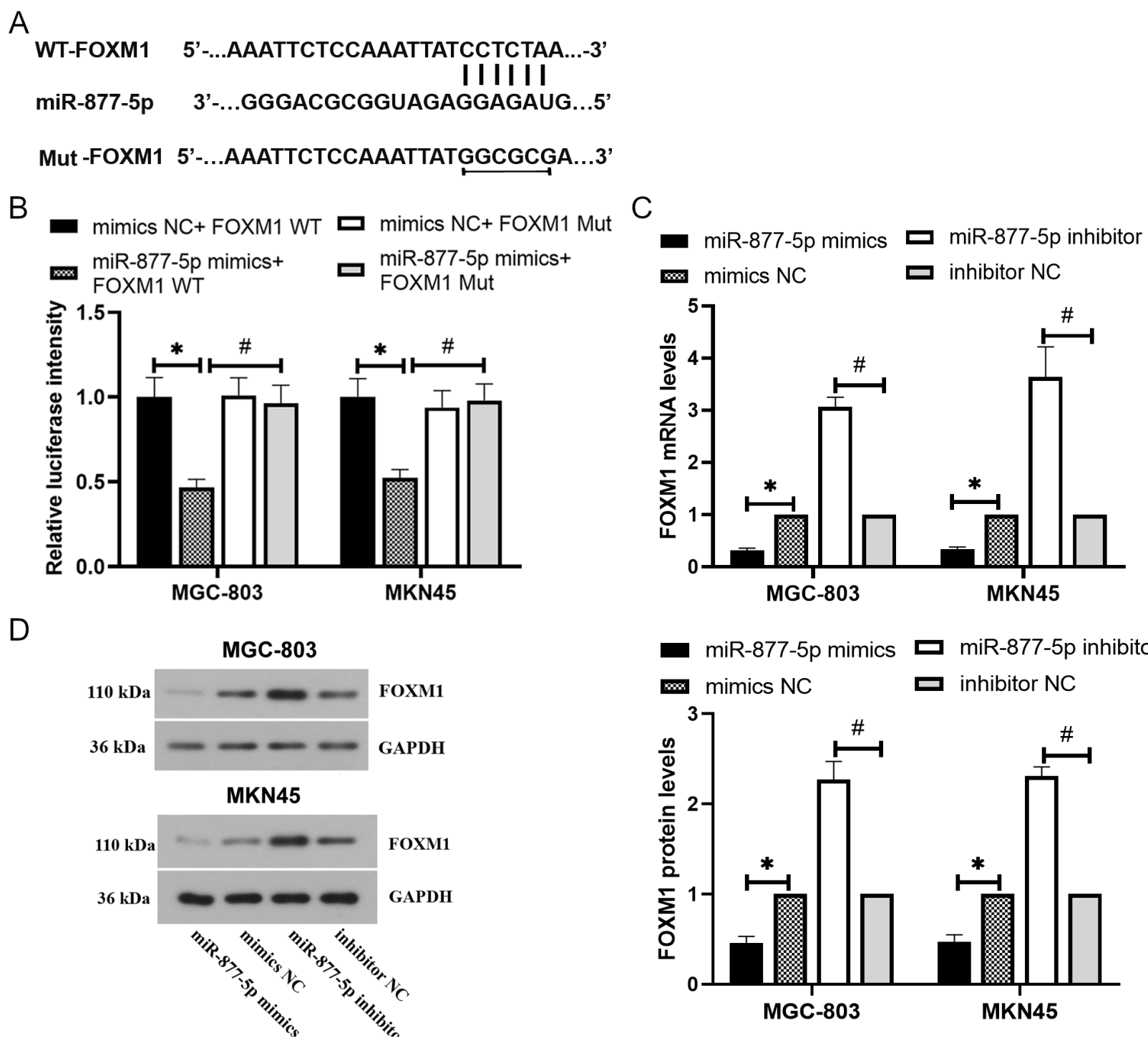

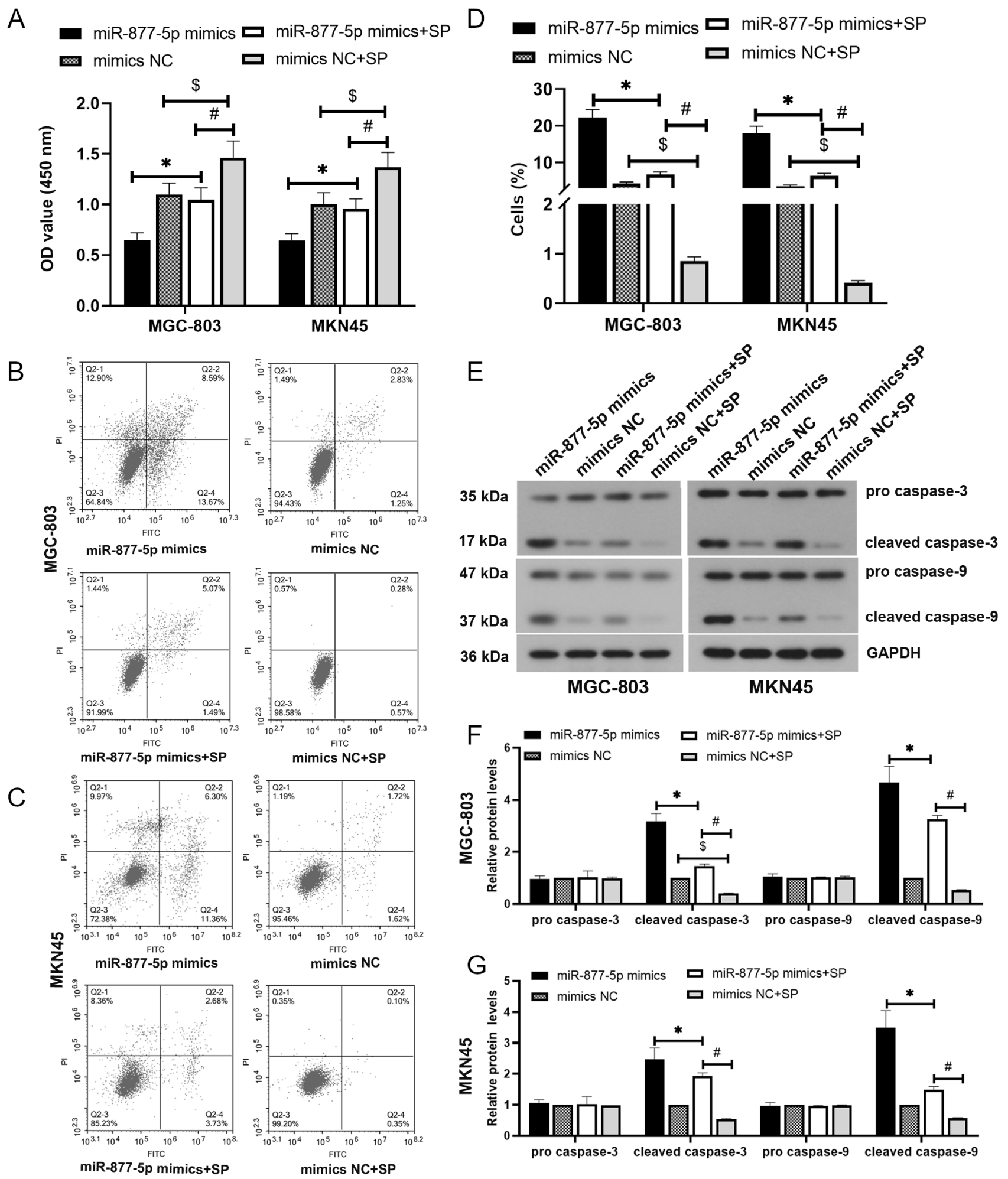

Figure 5. miR-877-5p overexpression antagonized the effect of SP on cell proliferation and apoptosis in gastric cancer. A) MGC-803 and MKN45 cell vitality after SP treatment of cells transfected with miR-877-5p mimics or mimics NC. B-D) Flow cytometry assay of apoptosis in MGC-803 and MKN45 cells. E) Representative immunoblots of pro caspase-3, cleaved caspase-3, pro caspase-9, and cleaved caspase-9 in MGC-803 and MKN45 cells. F, G) The relative amounts of protein were quantified by densitometry and normalized to the level of GAPDH in MGC-803 and MKN45 cells. Data are means $\pm \mathrm{SD}, \mathrm{n}=3$. ${ }^{*} \mathrm{p}<0.05$ compared with the miR-877-5p mimics group, ${ }^{*} \mathrm{p}<0.05$ compared with the mimics $\mathrm{NC}+\mathrm{SP}$ group, ${ }^{\$} \mathrm{p}<0.05$ compared with the mimics NC group. 
key executioners of apoptosis, partially or fully responsible for proteolytic cleavage of many key proteins [25]. Bcl-2 and related family members are involved in cell death induced by many stimuli, among them, Bcl-2 is an inhibitor of apoptosis, whereas Bax promotes apoptosis [26]. In the present study, we demonstrated that miR-877-5p can induce apoptosis in gastric cancer cells as evidenced by increased cleaved caspase-3, cleaved caspase-9, and Bax and decreased Bcl-2. Overall, the results suggested that miR-877-5p negatively regulates the development of gastric cancer through suppressing cell proliferation and inducing apoptosis.

As we all know, miRNAs participate in a variety of biological functions by negatively regulating downstream target genes. Previous studies found that the upregulation of miR-877-5p could inhibit the cell proliferation of hepatocellular carcinoma by targeting FOXM1. Here, we validated the targeting relationship between miR-877-5p and FOXM1 in gastric cancer. Moreover, miR-877-5p directly regulates the expression level of FOXM1 because it binds the 3'-UTR of FOXM1 mRNA complementarily to the seed region of miR-877-5p. FOXM1 is a member of the Fox family of transcription factors, and the overexpression of FOXM1 has been detected in a variety of cancer types [27, 28]. Besides, the FOXM1 regulatory network has been shown to be a major predictor of adverse outcomes in 18,000 cancer cases of 39 human malignancies [29]. Previous studies demonstrated that the overexpression of FOXM1 promoted cell migration, invasion, proliferation, and epithelial-mesenchymal transition in gastric cancer cells [30]. Silencing FOXM1 could promote apoptosis and autophagy in gastric cancer cells [31]. The findings indicated a vital role of FOXM1 in gastric cancer progression. Overall, we demonstrated that miR-877-5p may regulate cell proliferation and apoptosis in gastric cancer by targeting FOXM1.

SP is an undecapeptide and widely distributed in the body. It is derived from the prokinin A gene and belongs to the tachykinin family. It has been reported that SP plays a role as a carcinogen in the development of many cancers, including gastric cancer $[11,32]$. Especially, SP was associated with differentiation of gastric cancer and promoted proliferation, adhesion, migration, and invasion of gastric cancer cells [13]. Moreover, the long-term administration of SP significantly increased the incidence of gastric cancer in week 52 [14]. In the present study, we demonstrated that SP promotes the development of gastric cancer by increasing cell viability and suppressing apoptosis in gastric cancer cells, which is consistent with previous studies. Furthermore, there is evidence that miR-877-5p expression could be regulated by SP in the development of cancer [22]. Here, we further explored the relationship between miR-877-5p and SP in the development of gastric cancer. We demonstrated that SP not only promotes the development of gastric cancer but also decreases the expression of miR-877-5p, which was similar to previous studies on human colon epithelial cells [22]. Moreover, the miR-877-5p overexpression reversed the effect of SP on gastric cancer cell functions, including proliferation and apoptosis. The findings suggested that SP may play a promoting role in the development of gastric cancer by downregulating the expression of miR-877-5p. Besides, we proved that the FOXM1 expression level was positively correlated with SP in gastric cancer, indicating that SP may increase the level of FOXM1 by downregulating the expression of miR-877-5p.

Currently, NK-1 receptor antagonists targeting the SP/ NK-1R system are regarded as broad-spectrum anti-tumor drugs, of which aprepitant has been used in clinical practice and has anti-tumor effects on a large number of different human tumors, including gastric cancer [32,33]. The findings indicated the important significance of SP in the clinical treatment of cancer. In addition, FOXM1 has been reported to be highly expressed in gastric cancer cells and tissues and was associated with the prognosis of patients with gastric cancer [34]. In the present study, we demonstrated that SP promotes proliferation and inhibits apoptosis of gastric cancer cells by downregulating the level of miR-877-5p and further increasing the level of its downstream target gene FOXM1, which may be one of the reasons for the development of gastric cancer. More importantly, the miR-877-5p overexpression can antagonize the promoting effect of SP on the development of gastric cancer. Our findings indicate that miR-877-5p may be a potential therapeutic target for gastric cancer, and clarify the possible mechanism of SP involved in the development of gastric cancer, which provides a new direction for the clinical treatment of gastric cancer.

Acknowledgments: This study was supported by grants from the National Natural Science Foundation of China (No. 81670492) and the National Key Research and Development Project (No. 2016YFC132200).

\section{References}

[1] TORRE LA, BRAY F, SIEGEL RL, FERLAY J, LORTETTIEULENT J et al. Global cancer statistics, 2012. CA Cancer J Clin 2015; 2: 87-108. https://doi.org/10.3322/caac.21262

[2] KAMANGAR F, DORES GM, ANDERSON WF. Patterns of cancer incidence, mortality, and prevalence across five continents: defining priorities to reduce cancer disparities in different geographic regions of the world. J Clin Oncol 2006; 24: 2137-2150. https://doi.org/10.1200/JCO.2005.05.2308

[3] FERLAY J, SHIN HR, BRAY F, FORMAN D, MATHERS C et al. Estimates of worldwide burden of cancer in 2008: GLOBOCAN 2008. Int J Cancer 2010; 127: 2893-2917. https:// doi.org/10.1002/ijc. 25516

[4] ANG TL, FOCK KM. Clinical epidemiology of gastric cancer. Singapore Med J 2014; 55: 621-628. https://doi. org/10.11622/smedj.2014174

[5] SONG Z, WU Y, YANG J, YANG D, FANG X. Progress in the treatment of advanced gastric cancer. Tumour Biol 2017; 39: 1010428317714626. https://doi. org/10.1177/1010428317714626 
[6] YOSHIKAWA T, SATO T, YAMADA T, AOYAMA T, OGATA T et al. [Neoadjuvant Chemotherapy for Gastric Cancer]. Gan To Kagaku Ryoho 2016; 10: 1157-1160.

[7] HOKFELT T, PERNOW B, WAHREN J. Substance P: a pioneer amongst neuropeptides. J Intern Med 2001; 249: 27-40. https://doi.org/10.1046/j.0954-6820.2000.00773.x

[8] LEEMAN SE, MROZ EA. Substance P. Life Sci 1974; 15: 2033-2044. https://doi.org/10.1016/0024-3205(74)90020-4

[9] MAGGI CA, PATACCHINI R, ROVERO P, GIACHETTI A. Tachykinin receptors and tachykinin receptor antagonists. J Auton Pharmacol 1993; 13: 23-93. https://doi. org/10.1111/j.1474-8673.1993.tb00396.x

[10] PENNEFATHER JN, LECCI A, CANDENAS ML, PATAK E, PINTO FM et al. Tachykinins and tachykinin receptors: a growing family. Life Sci 2004; 74: 1445-1463. https://doi. org/10.1016/j.lfs.2003.09.039

[11] MUNOZ M, ROSSO M, CARRANZA A, COVENAS R. Increased nuclear localization of substance $\mathrm{P}$ in human gastric tumor cells. Acta Histochem 2017; 119: 337-342. https://doi. org/10.1016/j.acthis.2017.03.003

[12] ROSSO M, ROBLES-FRIAS MJ, COVENAS R, SALINASMARTIN MV, MUNOZ M. The NK-1 receptor is expressed in human primary gastric and colon adenocarcinomas and is involved in the antitumor action of L-733,060 and the mitogenic action of substance $\mathrm{P}$ on human gastrointestinal cancer cell lines. Tumour Biol 2008; 29: 245-254. https://doi. org/10.1159/000152942

[13] FENG F, YANG J, TONG L, YUAN S, TIAN Y et al. Substance $\mathrm{P}$ immunoreactive nerve fibres are related to gastric cancer differentiation status and could promote proliferation and migration of gastric cancer cells. Cell Biol Int 2011; 35: 623-629. https://doi.org/10.1042/CBI20100229

[14] TATSUTA M, IISHI H, BABA M, YANO H, ISEKI $\mathrm{K}$ et al. Promotion by substance $\mathrm{P}$ of gastric carcinogenesis induced by N-methyl-N'-nitro-N-nitrosoguanidine in Wistar rats. Cancer Lett 1995; 96: 99-103. https://doi.org/10.1016/03043835(95)03917-1

[15] BUSHATI N, COHEN SM. microRNA functions. Annu Rev Cell Dev Biol 2007; 23: 175-205. https://doi.org/10.1146/annurev.cellbio.23.090506.123406

[16] ZHOU X, YANG PC. MicroRNA: a small molecule with a big biological impact. Microrna 2012; 1: 1. https://doi. org/10.2174/2211536611201010001

[17] DI LEVA G, GAROFAlO M, CROCE CM. MicroRNAs in cancer. Annu Rev Pathol 2014; 9: 287-314. https://doi. org/10.1146/annurev-pathol-012513-104715

[18] SHI Q, XU X, LIU Q, LUO F, SHI J et al. MicroRNA-877 acts as a tumor suppressor by directly targeting eEF2K in renal cell carcinoma. Oncol Lett 2016; 11: 1474-1480. https://doi. org/10.3892/ol.2015.4072

[19] HUANG X, QIN J, LU S. Up-regulation of miR-877 induced by paclitaxel inhibits hepatocellular carcinoma cell proliferation though targeting FOXM1. Int J Clin Exp Pathol 2015; 8: $1515-1524$.

[20] YAN TH, QIU C, SUN J, LI WH. MiR-877-5p suppresses cell growth, migration and invasion by targeting cyclin dependent kinase 14 and predicts prognosis in hepatocellular carcinoma. Eur Rev Med Pharmacol Sci 2018; 22: 3038-3046. https://doi.org/10.26355/eurrev_201805_15061
[21] LI S, ZHU Y, LIANG Z, WANG X, MENG S et al. Correction: Up-regulation of $\mathrm{p} 16$ by miR-877-3p inhibits proliferation of bladder cancer. Oncotarget 2019; 10: 684. https://doi. org/10.18632/oncotarget.26624

[22] FANG K, SIDERI A, LAW IK, BAKIRTZI K, POLYTARCHOU $\mathrm{C}$ et al. Identification of a novel substance $\mathrm{P}$ (SP)-neurokinin-1 receptor (NK-1R) microRNA-221-5p inflammatory network in human colonic epithelial cells. Cell Mol Gastroenterol Hepatol 2015; 1: 503-515. https://doi. org/10.1016/j.jcmgh.2015.06.008

[23] XIE H, SHI S, CHEN Q, CHEN Z. LncRNA TRG-AS1 promotes glioblastoma cell proliferation by competitively binding with miR-877-5p to regulate SUZ12 expression. Pathol Res Pract 2019; 215: 152476. https://doi.org/10.1016/j. prp.2019.152476

[24] ELMORE S. Apoptosis: a review of programmed cell death. Toxicol Pathol 2007; 35: 495-516. https://doi. org/10.1080/01926230701320337

[25] COHEN GM. Caspases: the executioners of apoptosis. Biochem J 1997; 326: 1-16. https://doi.org/10.1042/bj3260001

[26] CHIPUK JE, MOLDOVEANU T, LLAMBI F, PARSONS MJ, GREEN DR. The BCL-2 family reunion. Mol Cell 2010; 37: 299-310. https://doi.org/10.1016/j.molcel.2010.01.025

[27] LAOUKILI J, STAHL M, MEDEMA RH. FoxM1: at the crossroads of ageing and cancer. Biochim Biophys Acta 2007; 1775: 92-102. https://doi.org/10.1016/j.bbcan.2006.08.006

[28] HALASI M, GARTEL AL. FOX(M1) news--it is cancer. Mol Cancer Ther 2013; 12: 245-254. https://doi. org/10.1158/1535-7163.MCT-12-0712

[29] GENTLES AJ, NEWMAN AM, LIU CL, BRATMAN SV, FENG $\mathrm{W}$ et al. The prognostic landscape of genes and infiltrating immune cells across human cancers. Nat Med 2015; 21: 938-945. https://doi.org/10.1038/nm.3909

[30] MIAO L, XIONG X, LIN Y, CHENG Y, LU J et al. Downregulation of FoxM1 leads to the inhibition of the epithelial-mesenchymal transition in gastric cancer cells. Cancer Genet 2014; 207: 75-82. https://doi.org/10.1016/j.cancergen.2014.02.008

[31] YU W, CUI X, WAN Z, YU Y, LIU X et al. Silencing forkhead box M1 promotes apoptosis and autophagy through SIRT7/ mTOR/IGF2 pathway in gastric cancer cells. J Cell Biochem 2018; 119: 9090-9098. https://doi.org/10.1002/jcb.27168

[32] COVENAS R, MUNOZ M. Cancer progression and substance P. Histol Histopathol 2014; 29: 881-890. https://doi. org/10.14670/HH-29.881

[33] ISHIDO K, HIGUCHI K, AZUMA M, SASAKI T, TANABE $S$ et al. Aprepitant, granisetron, and dexamethasone versus palonosetron and dexamethasone for prophylaxis of cisplatin-induced nausea and vomiting in patients with upper gastrointestinal cancer: a randomized crossover phase II trial (KDOG 1002). Anticancer Drugs 2016; 27: 884-890. https:// doi.org/10.1097/CAD.0000000000000385

[34] LI X, MA K, SONG S, SHEN F, KUANG T et al. Tight correlation between FoxM1 and FoxP3+ Tregs in gastric cancer and their clinical significance. Clin Exp Med 2018; 18: 413-420. https://doi.org/10.1007/s10238-018-0505-6 